\title{
The Feasibility of Using Marble Cutting Waste in a Sustainable Building Clay Industry
}

\author{
Medhat S. El-Mahllawy ${ }^{1, *}$, Ayman M. Kandeel ${ }^{1}$, Mahmoud L. Abdel Latif ${ }^{1}$ \\ and Abdeen M. El Nagar ${ }^{1}$ \\ ${ }^{1}$ Raw Building Materials and Processing Technology Research Institute, \\ Housing and Building National Research Center (HBRC), Egypt. \\ 87 El-Tahreer St., Dokki, Giza, Egypt., P.O. Box 1770 Cairo. \\ *Correspondence: geo_mahmoud@hbrc.edu.eg, medhatt225@yahoo.com.
}

\begin{abstract}
This study evaluates the feasibility of stabilizing clay bricks with marble cutting waste (MCW). This waste currently discarded in huge quantities as a sludge resulted from sawing the marble blocks to slabs, grinding and polishing of marble processes to the landfills located around the marble processing factories located in the Shaq El-Thoban industrial zone, Cairo governorate, Egypt causing negative impacts on the environment, health and sustainable development. Experimental investigations were carried out to explore the effect of addition of the MCW in different clay-base mixes at different percentages up to $25 \%$ at the expense of the hydrated lime. Cement, hydrated lime and MCW are the three types of solidification agents used, clay and sand were also added in the formulations of the unfired clay brick specimens. Laboratory cylindrical stabilized and compressed specimens were made, and then they were cured in a humidity chamber for 2 and 4 weeks, then after were air dried, tested and evaluated according to the Egyptian code for the building by the stabilized and compressed earth soil (ECBS, 2016). To enhance the durability of the cured specimens, transparent silicon - based paint was used for this purpose. The laboratory results demonstrate high potential usage of MCW based additives up to $15 \%$ incorporating HL. In addition, the used paint could be an effective treatment way for the use of stabilized bricks in a wet environment. The use of eco-friendly building materials will be a great contribution for the environmental advantages and suggest a remarkable economical alternative to the fired building units.
\end{abstract}

Keywords: Marble cutting waste, stabilized clay bricks, hydrated lime, Shaq El-Thoban. 


\section{Introduction}

In Egypt, clay brick is the most common construction materials used for the historical and traditional buildings for a long time. Conventional bricks are produced from clay with high firing temperature or from ordinary Portland cement with aggregates. The high temperature used or the clay bricks and cement processing industries consumes a significant amount of energy and releases a large quantity of greenhouse gases to the atmosphere leading to environmental and economical problems. In the clay brick industry, about $0.41 \mathrm{~kg}$ of carbon dioxide is released per brick [1]. In the cement industry, production of OPC is responsible for about $7 \%$ of all $\mathrm{CO}_{2}$ generated worldwide [2]. So, for environmental protection and sustainable development, many researchers have studied the utilization of waste materials and industrial by-products to make eco-friendly building bricks using different methods, materials and stabilizers [3-10] and others.

Several positive reactions occur when lime is added to clay in the presence of water; cation exchange, flocculation-agglomeration, carbonation, and pozzolanic reaction [11]. On contrast, two deleterious chemical reactions probably occur in the lime treated soil [12]. The first is the lime carbonation and the second is the reaction with the sulfate salt existing in the soil. Calcite crystals are formed due to the carbonation process, it is considered cementing material but it should control their formation. This is due to three main reasons; it has weak bonding force, calcium carbonate is a soluble salt when exposed to air for a long time period and carbonation process consumes calcium ions which affected negatively on role of lime on the pozzolanic reaction progress.

In Africa, compressed stabilized earth bricks are widely used in construction as the most efficient way for many advantages [13]. Sustainability is to use waste materials and by-products produced from other industrial activities in a green useful application. In this research, during the cutting stage of the Egyptian marble processing industry the marble waste $(\mathrm{MCW})$ is generated in the form of fine particles as aqueous sludge. In Egypt, the main area where most of marble factories and manufacturing plants are found are located in the Shaq El-Thoban industrial zone, Cairo governorate. It contains about 400 factories and 3000 manufacturing workshops [14]. These manufacturing places produce nearly in the range of $3-4$ million tones of marbles and granites products that generate about 800 thousands -1.0 million tons of marbles and granite wastes per year [15]. The large quantities of studied waste currently is discarded daily to the open landfills that surrounded the industrial zone as a liquid slurry waste resulted from sawing the marble blocks to slabs, grinding and polishing of marble processes to be air dried causing negative impacts on the environment, health and sustainable development. So, the main objective of this study is to evaluate the feasibility of stabilizing the clay-based bricks with the Egyptian marble cutting waste (MCW) for economical, environmental and health concerns.

\section{Experimental Procedures}

\subsection{Materials}

Five different materials were used in this study; Kafr Homied clay (KHC), sand, ordinary Portland cement (OPC), marble cutting waste (MCW) and hydrated lime (HL). The used clay and sand samples were collected from the clay and sand quarries located beside Kafr Homied village, 50km south of Cairo, Giza governorate, Egypt. In the field, the used clay is grayish green color, massive, damped and some gypsum lamina of different directions and iron oxide spots are included within the claystone deposits of the Late Eocene age [16]. The Portland cement used was of CEM (I) 42.5 type and locally manufactured and supplied by the Suez Cement Company, Egypt. The used hydrated lime was purchased from the most found type in the Egyptian market. The marble waste used in this investigation is delivered as air dried 
powder residual from the marble landfill at Shaq El-Thoaban area, east of Auto Ostrad Rd., Cairo governorate (Fig.1). It is the largest marble and granite industrial cluster in Egypt and the fourth worldindustrial zone. Also, a silicon- based paint was used in this study for the specimens treatment to increase their durability. It was got from the CMB (chemicals for modern buildings) group, exterior paint products, Egypt.
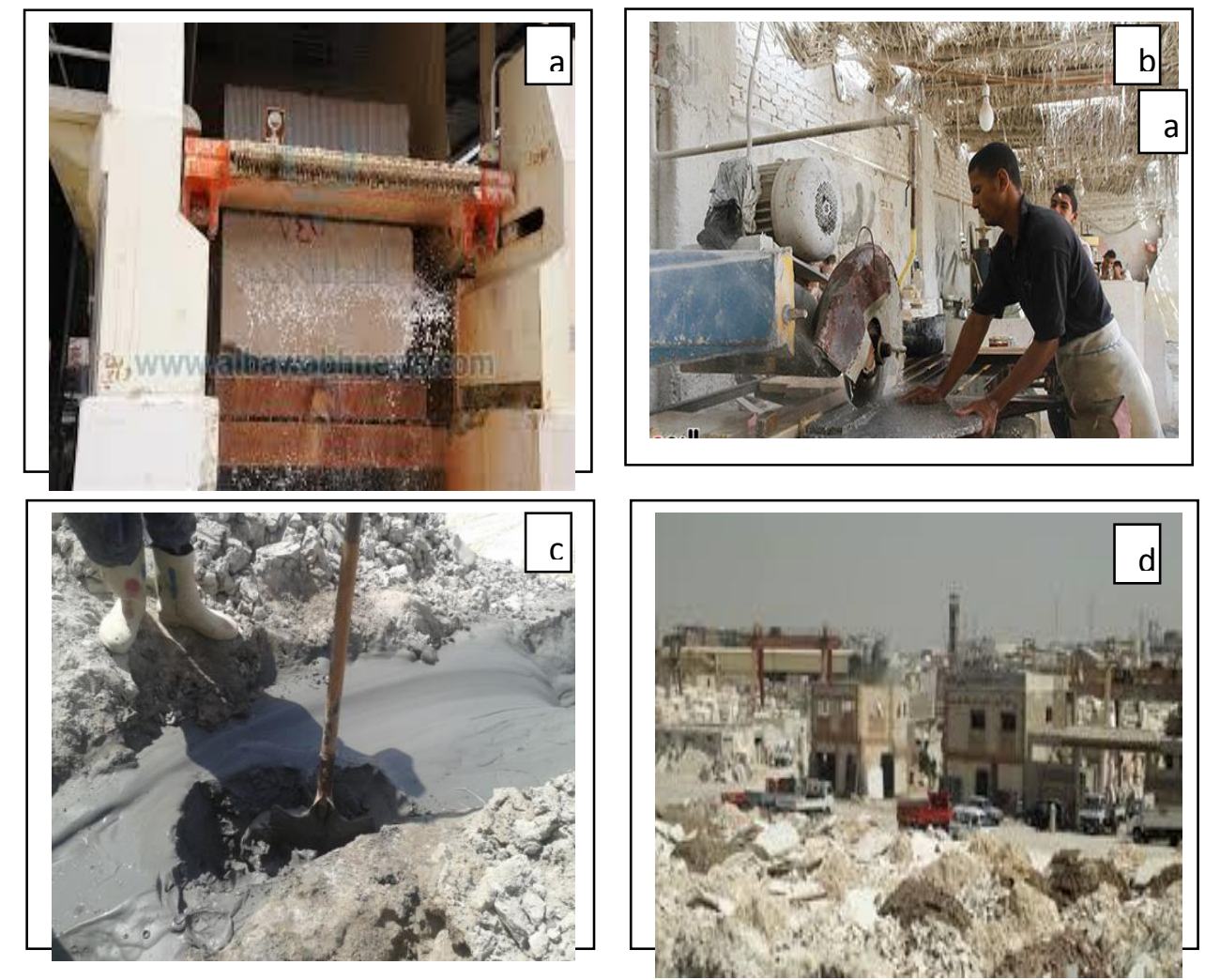

Fig. 1. Photographs showing types of the cutting processes (a \& b), marble cutting sludge (c), landfill of the marble sludge and cuttings in a vacant area near Shaq El-Thoaban industrial zone (d), Cairo, Egypt.

\subsection{Methods}

Selective samples from the used materials and unfired cylindrical clay specimens were analyzed by the powder X-ray diffraction (XRD) for mineralogical characterization. The used XRD apparatus was a X'Pert PRO PW3040/60 (PANalytical) diffractometer equipped with monochromatic $\mathrm{Cu}-\mathrm{K} \alpha$ radiation source. The test was run at $40 \mathrm{kV}$ and $30 \mathrm{~mA}$. The acquired data were identified using X'Pert high score software works with a PDF-2 database. The chemical composition (major oxides) of the raw materials and investigated mixes were determined by the X-ray fluorescence (XRF). The used XRF was an Axios sequential spectrometer manufactured by PANalytical, Netherlands. Also, traditional manual method prescribed in the American Society of Testing and Materials (ASTM) for determination of the loss on ignition [17], (LOI) was followed. Particle size distribution of the used materials was determined using laser diffraction analyzer (manufactured by Horiba, LA-950, France). Furthermore, the pH value was measured at $20^{\circ} \mathrm{C}$ by an electronic $\mathrm{pH}$ meter (Jenway 3510, UK) following the ASTM test method [18]. Also, the formed phases in the cured specimens were identified using Jasco-6100 Fourier transformed infrared spectrometer (FTIR; Varian model, Excalibur FTS 3000MX, Paolo Alto, CA). The tested 
samples were prepared using the $\mathrm{KBr}$ pressed disc technique. The analysis was done between 400 and $4000 \mathrm{~cm}^{-1}$.

\subsection{Mix composition and specimen preparation}

In order to investigate the effect of the used MCW, five mixtures, namely R (raw mix), R 1, R 2, R 3 and $\mathrm{R} 4$ were designed for the study as given in Table 1 . The MCW addition was at the expense of the HL percentage which acts as the main stabilizer. The Portland cement was added in a small percentage, for economical and environmental concerns, to accelerate the initial setting. The sand as non-plastic material was used to make the final product durable [19] in addition, to reduce the effect of shrinkage of the clay that may occurs as well as it may accelerate the formation of hydration products [20]. All the used materials, before the experimental work, were passed through 300 micron sieve diameter.

Table 1. Composition, proportion and $\mathrm{pH}$ of the studied mixes

\begin{tabular}{|c|c|c|c|c|c|c|}
\hline \multirow{2}{*}{$\begin{array}{c}\text { Mix } \\
\text { code }\end{array}$} & \multicolumn{5}{|c|}{ Mix ingredient, \% } & \multirow{2}{*}{} \\
\cline { 2 - 6 } & Clay & Sand & HL & MCW & OPC & pH \\
\hline R & 75 & 25 & 0 & 0 & 0 & 6.7 \\
\hline R 1 & 50 & 25 & 20 & 0 & 5 & 12.8 \\
\hline R 2 & 50 & 25 & 10 & 10 & 5 & 12.5 \\
\hline R 3 & 50 & 25 & 5 & 15 & 5 & 12.4 \\
\hline R 4 & 50 & 25 & 0 & 20 & 5 & 11.5 \\
\hline
\end{tabular}

Mixing process of the mix was started by the thoroughly mixing of the ingredients of each mix by manual shaking and overturning the plastic bag for at least $2 \mathrm{~min}$. The water was added gradually to the prepared mixture, approx. $\sim 16 \%$ of the total mix wt. gave good molding consistency, in a laboratory mixer and mixed for at least 3 min to obtain a homogenous mixture as possible and to ensure the uniformity of the mixture. Hereafter, the mix was placed in a cylindrical mold of $25 \mathrm{~mm}$ in diameter and $50 \mathrm{~mm}$ in height, and compressed using a static hydraulic compression machine under 10.0MPa pressure. Consequently, the specimens were demolded $\sim 10 \mathrm{sec}$ after completion of the compaction, labeled and stored in a controlled humidity chamber at $40^{\circ} \mathrm{C} \pm 2$ and $80 \% \pm 2$ relative humidity $(\mathrm{RH})$ until the testing periods of 14 and 28 days. Five sets of compacted specimens were laboratory made. The cured specimens were air dried for 3 days prior to tests. However, dynamic compaction can reduce the optimum water content from $12 \%$ to $10 \%$ with about $50 \%$ increase in the compressive strength and optimum water content range between 10 to $13 \%$ for static compaction [21].

\subsection{Testing procedures}

At the end of the curing period a series of tests was carried out in order to determine the primary engineering properties for the air-dried specimens in terms of water absorption, bulk density, soaking test and compressive strength. To simulate the manufacturing process, before every test, the specimens were dried naturally for 3 days at the lab ambient condition (air-dried specimen). The specimen's tests were carried out according to the following formulations: Water absorption test was measured using the relation $(\mathrm{Ms}-\mathrm{Md}) /(\mathrm{Md})$, where $\mathrm{Ms}$ is the mass of saturated-dry specimen $(\mathrm{g})$ after 24-h water soaking and $\mathrm{Md}$ is the mass of the air- dried specimen $(\mathrm{g})$. The bulk density of the specimens was determined by dividing mass of the air-died specimen $(\mathrm{g})$ over the volume of cylindrical specimen $\left(\mathrm{cm}^{3}\right)$. 
The compressive strength test was calculated by dividing the maximum load to failure (kg) by the area of the bearing surface $\left(\mathrm{cm}^{2}\right)$ of a specimen. To evaluate durability of the specimens, the air-dried specimens of different mixes at different curing periods were soaked completely in tap water for $24 \mathrm{~h}$ and the result was visually assested. Also, to enhance to specimens durability the 14 days air dried specimens were surface treated by a silicon-based paint and the water soaking test was carried out again. All the air- dried and treated specimens were tested for water absorption, bulk density, soaking test and compressive strength and average of three test results was recorded, if available. The test results were evaluated in accordance with the Egyptian code for the building by the stabilized soil [22].

\section{Results and Discussion}

\subsection{Characteristics of the raw materials}

The chemical composition, loss on ignition (LOI) and $\mathrm{pH}$ of the used materials are given in Table 2. The used quicklime (HL) is not a fatty lime $(\mathrm{CaO}<85 \%)$ according to the Egyptian standard specification [23]. The XRD patterns of the used clay, sand and OPC are illustrated before [24]. The chemical composition of the $\mathrm{KHC}$ shows about $3 \%$ of $\mathrm{SO}_{3}$ expecting the presence of sulfate-based mineral (gypsum) as confirmed by the XRD analysis. The MCW consists mainly of $\mathrm{CaO}$ content with minor percentages of the others oxides and traces / minor contents of chloride ion, alkalis and iron oxide. The $\mathrm{pH}$ of the MCS is slightly alkaline. Fig. 2 shows the XRD pattern of the used MCW. The pattern confirms the results of the chemical analysis where the waste is composed mainly of calcite mineral $\left(\mathrm{CaCO}_{3}\right)$ and traces of quartz $\left(\mathrm{SiO}_{2}\right)$ mineral is also detected.

Fig. 3 presents the particle size distribution analysis of the used MCW. The pattern shows bimodal peaks representing the biggest quantitative percentages that found at $5.0 \%$ and $4.5 \%$. $90 \%$ of the particles size is under $21.4 \mu \mathrm{m}$ and the biggest particles size is $262.3 \mu \mathrm{m}$. Also, the mean particles size is $13.1 \mu \mathrm{m}$. The result illustrates that the tested MCW particles are within the medium silt size class.

\subsection{Mineralogy of the cured specimens of different mixes}

Figs. 4 and 5 represent XRD patterns of the clay-based specimens of different mixes cured for 2 and 4 weeks, respectively. It was observed as the MCW increases to less than $20 \%$, in the presence of the HL. The peaks of clay minerals decreased and finally disappeared as shown in the mix R3. The lack of clay minerals suggests their destruction and formation of cementing and poorly crystalline gels. The reaction between the released soluble compounds and the calcium ions from the lime hydration creates cementitious materials such as $\mathrm{C}-\mathrm{S}-\mathrm{H}$ gel and $\mathrm{C}-\mathrm{A}-\mathrm{H}$ [25]. These pozzolanic reactions are time dependent and require a long time. This is due to such reactions are functions of temperature, calcium quantity, $\mathrm{pH}$ value and quantity of the soluble compounds.

It is worth mentioning that the quartz has a decreased intensity with the increase of MCW content as well as curing days. This means that the pozzolanic reaction is progressed. The decrease of quartz crystallinity is presumably due its solubility in the alkaline medium (R1 to R3) which is linked to the increase of $\mathrm{pH}$. Also, it was found that with increasing of $\mathrm{MCW}$ addition the calcite becomes well crystallized. The XRD pattern of the mix R4 shows a well crystalline $\mathrm{CaCO}_{3}$ as $\mathrm{MCW}$ increases. Calcite has weak cementing bond and it is affected negatively on pozzolanic reaction. It is believed that the ettringite is formed may be due to the chemical reaction between calcium ions (MCW) and aluminum solubilized from the clay in the present of soluble sulfate (gypsum) in the presence of humidity for a long period. This formation is promoted in the absence of HL. 
Table 2. Chemical compositions in terms of oxide content, loss on ignition and $\mathrm{pH}$ of the raw used materials, wt.

\begin{tabular}{|c|c|c|c|c|c|}
\hline $\begin{array}{c}\text { Oxide } \\
\text { content }\end{array}$ & $\begin{array}{c}\text { Hydrated } \\
\text { lime (HL) }\end{array}$ & $\begin{array}{c}\text { Ordinary } \\
\text { Portland cement }\end{array}$ & Clay & Sand & $\begin{array}{c}\text { Marble cutting } \\
\text { waste (MCW) }\end{array}$ \\
\hline $\mathbf{S i O}_{\mathbf{2}}$ & 1.69 & 20.59 & 49.95 & 93.88 & 0.52 \\
\hline $\mathbf{A l}_{\mathbf{2}} \mathbf{O}_{\mathbf{3}}$ & 1.11 & 4.02 & 22.51 & 3.86 & 0.12 \\
\hline $\mathbf{F e}_{\mathbf{2}} \mathbf{O}_{\mathbf{3}}$ & 0.24 & 3.31 & 6.87 & 0.68 & 0.18 \\
\hline $\mathbf{C a O}$ & 70.52 & 62.71 & 1.64 & 0.65 & 56.35 \\
\hline $\mathbf{M g O}$ & 0.75 & 1.95 & 1.22 & 0.37 & 0.35 \\
\hline $\mathbf{N a}_{\mathbf{2}} \mathbf{O}$ & 0.01 & 0.47 & 3.11 & 0.21 & 0.05 \\
\hline $\mathbf{K}_{\mathbf{2}} \mathbf{O}$ & 0.05 & 0.18 & 0.92 & 0.09 & 0.04 \\
\hline $\mathbf{S O} \mathbf{O}_{\mathbf{3}}$ & 0.14 & 2.95 & 3.12 & 0.02 & 0.01 \\
\hline $\mathbf{L . O . I}$ & 25.69 & 3.81 & 10.28 & 0.23 & 42.38 \\
\hline $\mathbf{p H}$ & 12.82 & 13.52 & 6.72 & 7.11 & 8.13 \\
\hline $\mathbf{C l}$ & $\mathrm{Nil}$ & $\mathrm{Nil}$ & 0.86 & $\mathrm{Nil}$ & 0.01 \\
\hline
\end{tabular}

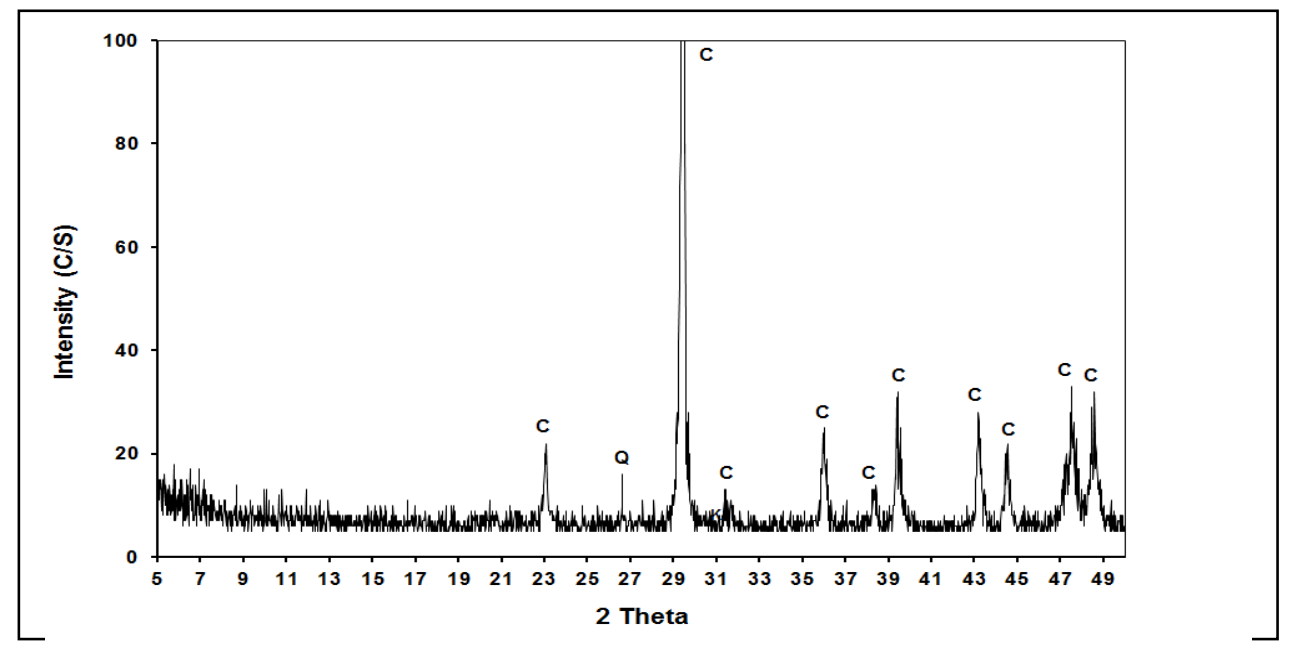

Fig. 2. XRD pattern of the used MCW. (C: Calcite, Q: Quartz).

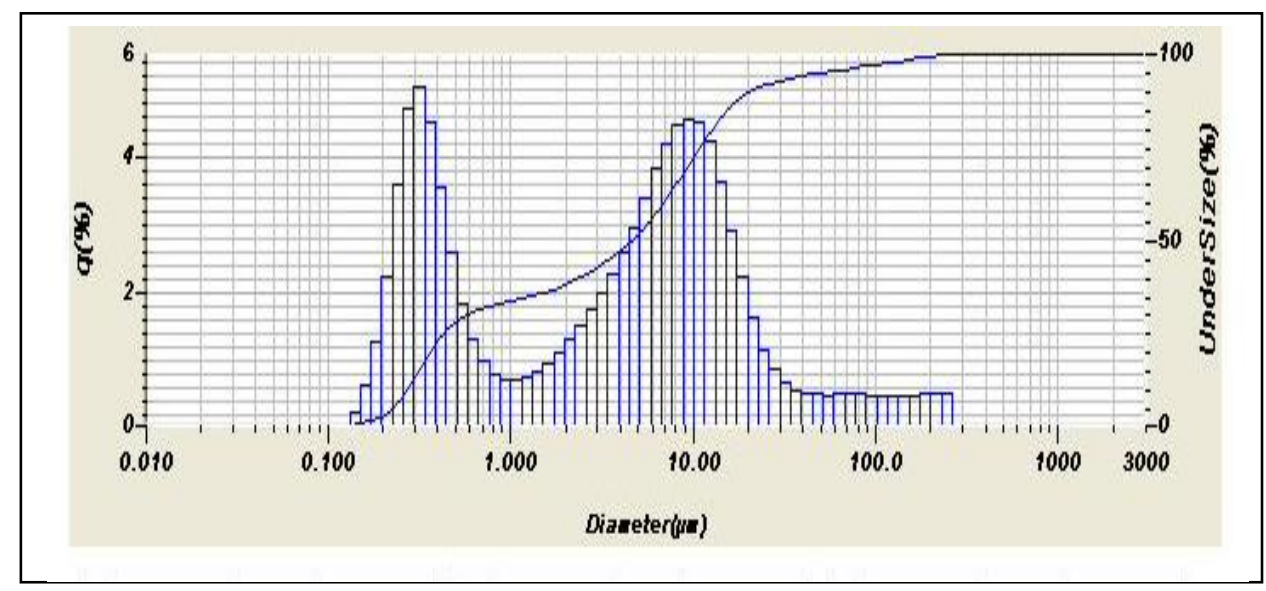

Fig. 3. Particle size analysis of the used MCW. 
The excessive amount of calcite as appeared in the specimens of the mix R4 limited the formation of the cementing hydrated compound and form heterogeneous microstructure. Also, it was observed with vanishing of the main stabilizer (HL) in the mix R4 the ettringite and gypsum phases appear. The ettringite formation will leads to the increase of the soil volume, water absorption, reduction of effective cohesion and soil strength loss [26].

The high $\mathrm{pH}$ value creates favorable condition for local dissolution of the likely releasing alumina and silica within the specimen body. Furthermore, the silica and alumina that exist in the clay minerals become soluble and free from the clay body when $\mathrm{pH}$ exceeds 12. [12]. So, the specimens of mix R4 have no pozzolanic reaction. This is supported by the re-presence of clay minerals of kaolinite and montmorillonite. The significant change in the XRD patterns of the studied mixes cured for 2 and 4 weeks was found for the quartz peaks that have less intensity in the 4 weeks giving evidence to the pozzolanic reaction progressing as quartz dissolution. This may be attributed to the low crystallinity of the formed cementing phases especially in the early stages of formation [27].

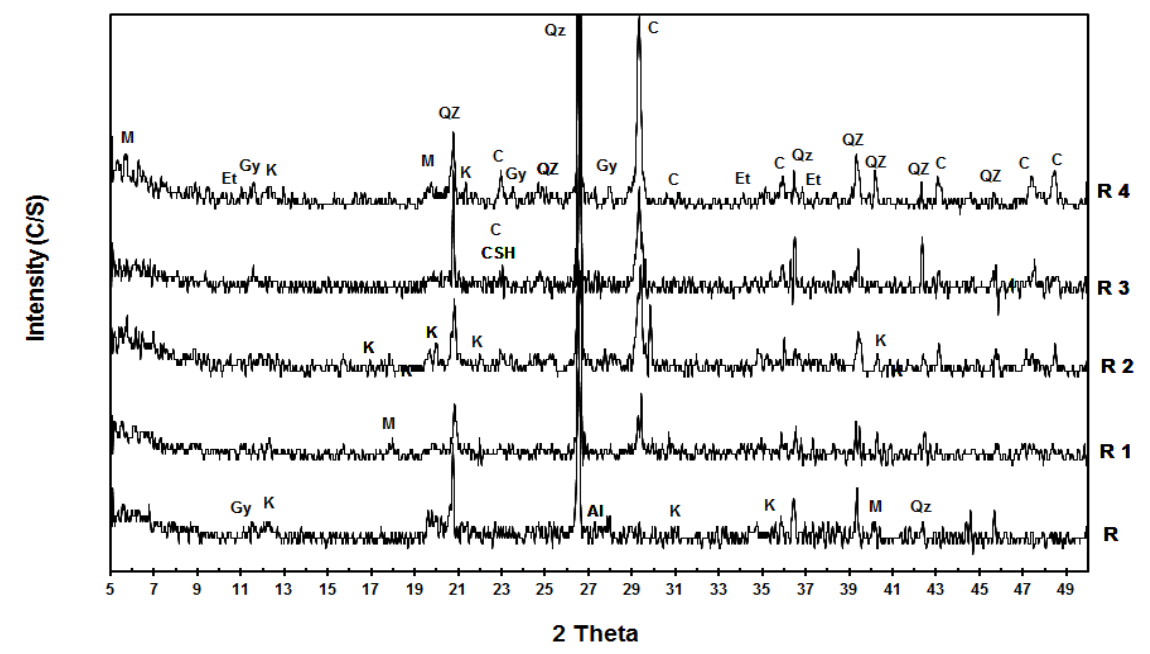

Fig. 4 . XRD patterns of the 2 weeks cured specimens of different mixes. M:Montmorillonite (Et: Ettringite, Gy: Gypsum, K: Kaolinite, Qz: Quartz, C: Calcite, CSH: Calcium silicate hydrate, Al: Albite).

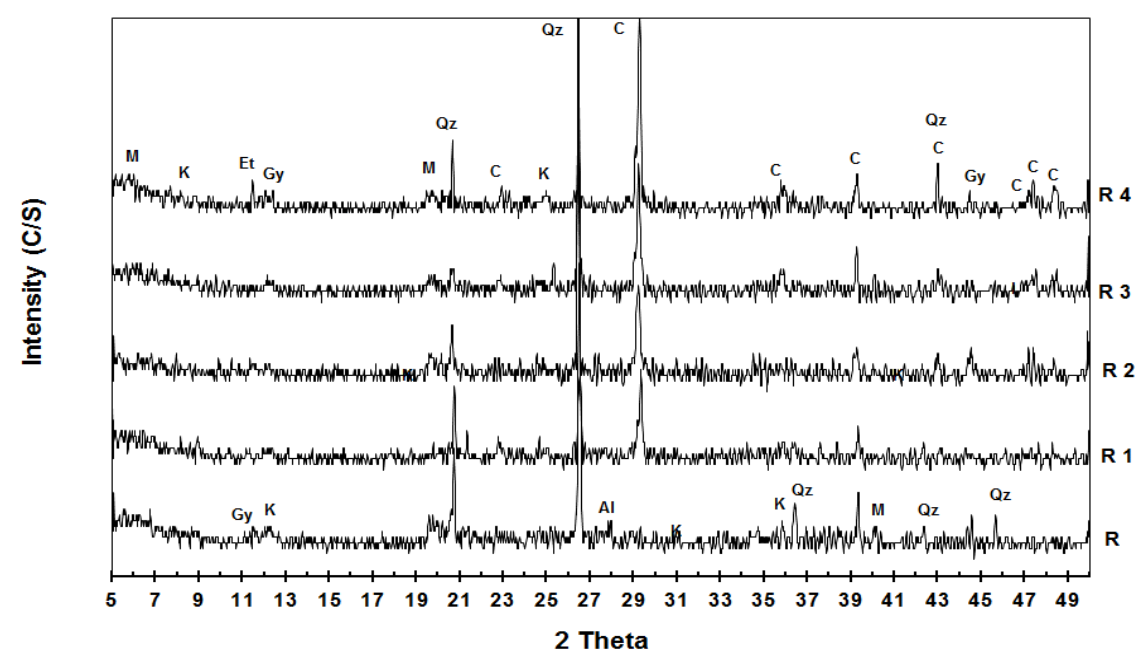

Fig.5. XRD patterns of the 4 weeks cured specimens of different mixes. 


\subsection{Physico-mechanical properties of the cured specimens}

Fig. 6 shows the results of the water absorption, bulk density, and dry/wet compressive strength of the specimens of different mixes cured for 2 and 4 weeks. Fig. 7 represents the effect of the treatment on the properties of the 2 weeks cured specimens of different mixes. Table 3 records the soaking test results of the specimens cured for 2 and 4 weeks and the results of the 2 weeks cured specimens after the treatment.

- Results of the Fig. 6 show that the water absorption decreased as the curing period increased. Also, water absorption test can't be determined for the specimens of the mix R (without stabilizers) due to their collapsibility behavior in water. The amount of the absorbed water decreased as the MCW dosage increased giving evidence that the MCW plays a significant role in the impermeability of the tested specimens in the presence of the HL. It reached the best value $(10.1 \%)$ in the R3 specimens (15\% $\mathrm{MCW}+5 \% \mathrm{HL}$ ) cured for the 4 weeks. This is probably due to the pozzolanic reaction development as detected obviously in the XRD patterns which leads to the formation and accumulation of cement phases that close some of the open pores then decreases their affinity to absorb water. All the specimens of mixes R1-R3 cured for 2 and 4 weeks achieved the ECBS requirements (class A: 8-10, class B: 10-12 and class C: $12-15 \%)$.

- In terms of bulk density (Fig.6) of the clay-based specimens, it is increased with curing period as well as the MCW addition till the mix R3. The specimens of the mix R4 show the lowest density rather than the other mixes. The bulk density increases is indicative for the pozzolanic reaction progressing and phases formation and vice versa. The highest value achieved by the specimens of the mix R3 that cured for 4 weeks. In other words, as the MCW content increases at the expense of the HL, the bulk density increases giving evidence for densification.

- Fig. 6 pointed that the compressive strength increases with the prolongation of curing period and MCW content increasing till the mix R3. Dry compressive strength values are remarkable higher than those of the wet results. Wet compressive strength of the specimens of the mixes R and R4 at all curing periods can't be determined due to their collapsing in water. This is attributed to the breakdown of weak chemical bonds between stabilized constituents. The soluble lime ions have slow setting time and gain its strength overtime. In terms of comparing the strength development, the $\mathrm{MCW}$ is more effective incorporating a low content of the HL. However, when the MCW dosage was too high (20\%) and without the HL, the strength gained was too low. The highest value $\left(167.5 \mathrm{~kg} / \mathrm{cm}^{2}\right)$ achieved by the specimens of the mix R3 that cured for 4 weeks. All the specimens of mixes R1-R3 cured for 2 and 4 weeks achieved the ECBS requirements of the dry and wet compressive strengths (dry compressive strength; class A: 50-70, class B: 40-60 and class C: 30-50\%, and wet compressive strength; class A: 30-40, class B: 20-30 and class C:15$20 \mathrm{~kg} / \mathrm{cm}^{2}$ ). The MCW may acts as water repellent material.

- In order to enhance the specimens properties of different mixes in terms of water absorption, wet compressive strength and resistivity the effect of water, the 2 weeks cured specimens were treated by a silicon- based transparent construction paint, where they have the lowest properties values. The used material is painted on the external surfaces of the specimens, thus it gives when dry; an invisible waterproof protection repels rain drops which slide over surfaces and wash away dust and other pollution. - A comparative analysis between the obtained results was established and were represented graphically in Fig.7 and given in Table 3. As shown in Fig. 7, all the studied properties are clearly enhanced. The water absorption decreased after the treatment obviously. This means that the treatment is effective and closed and the results of the 2 weeks cured specimens after the treatment. The open pores and / or coats the external surfaces. Furthermore, where the used liquid has low viscosity and eases to penetrate inside the specimens and has a low density $(1.0 \mathrm{~kg} / \mathrm{l})$, the specimens bulk density are decreased and their durability 
are increased as compared with the 2 weeks cured specimens without treatment. However, the working mechanism of the added liquid does not affect the compressive strength of the specimens but it works on the surface protection and particles coating.

- Results given in Table.3 indicated the improvement of the resistivity to water collapsibility as appeared in the specimens of mixes R, R1 and R4. The results emphasize the importance of the use of surface protection paints. This means the possibility of using of the compressed and stabilized bricks in semi- rain regions but it may needs to evaluate the durability against water erosion using the spray test method.
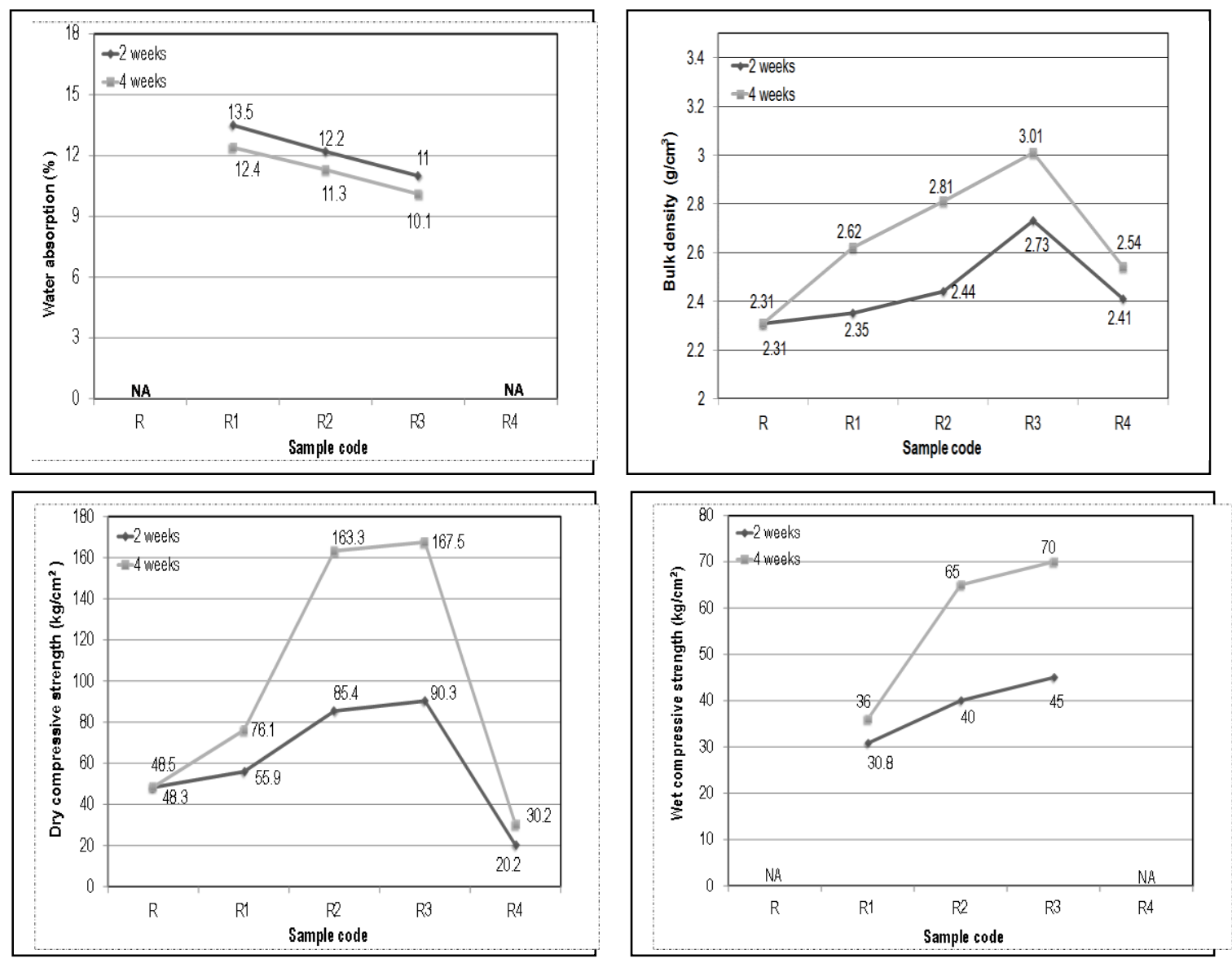

Fig. 6. Water absorption, bulk density, dry and wet compressive strength of the specimens of different mixes cured for 2 and 4 weeks. 

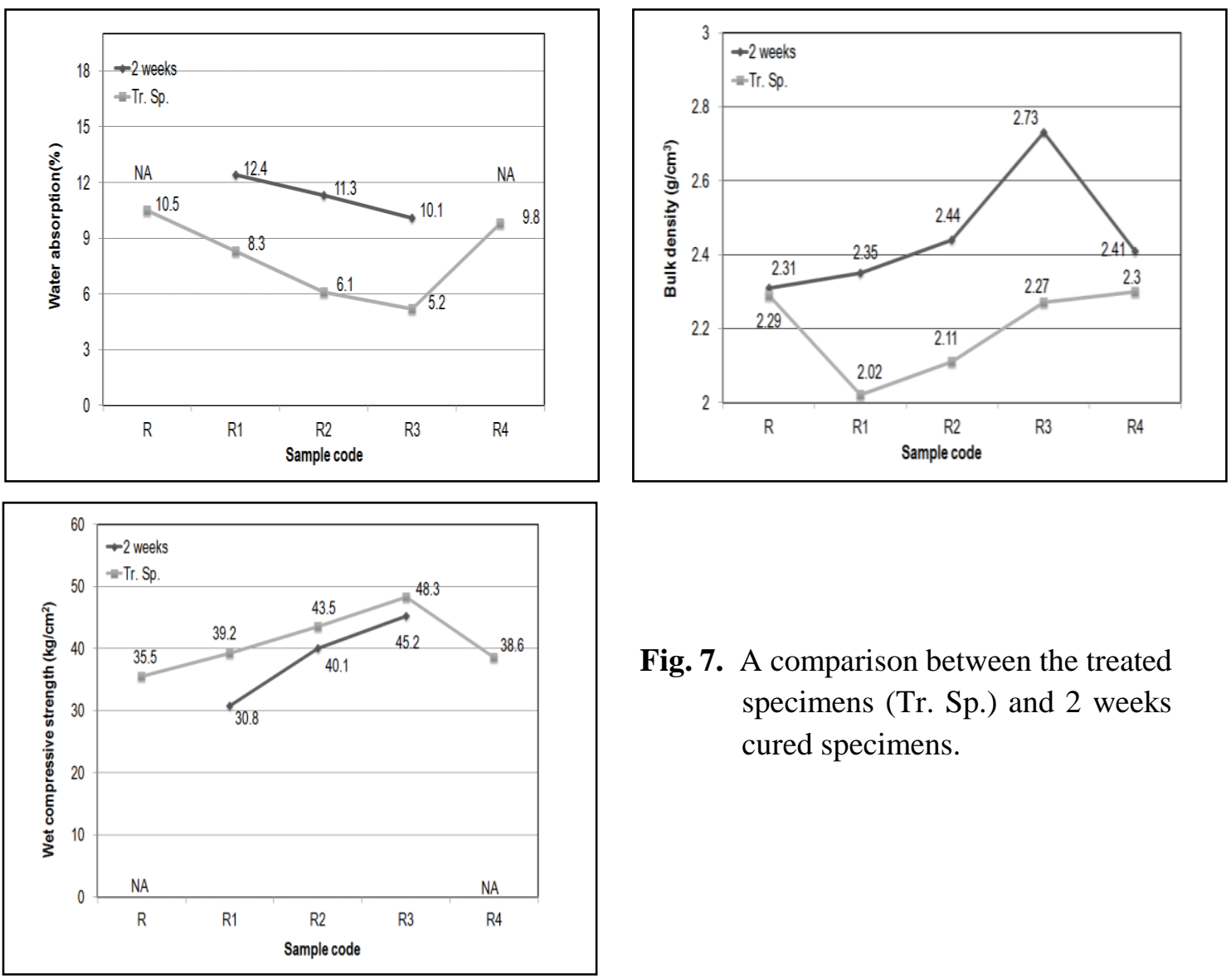

Fig. 7. A comparison between the treated specimens (Tr. Sp.) and 2 weeks cured specimens.

Table 3. Result of water soaking test of the cured specimens of different mixes before and after the treatment.

\begin{tabular}{|c|c|c|c|}
\hline \multirow{2}{*}{$\begin{array}{c}\text { Specimens of } \\
\text { the mix }\end{array}$} & \multicolumn{3}{|c|}{ Status of the specimens that cured for } \\
\cline { 2 - 3 } & \multicolumn{2}{|c|}{2 weeks } & 4 weeks \\
\cline { 2 - 3 } & Before & After & C \\
\hline R & C & PF & PF \\
\hline R 1 & PF & ND & ND \\
\hline R 2 & ND & ND & ND \\
\hline R 3 & ND & ND & C \\
\hline R 4 & C & ND & \\
\hline
\end{tabular}

ND: No damage, PF: Partial failure (after a while), C: Completely failure 


\subsection{Results of the FTIR analysis of the cured specimens of different mixes}

Figs. 8 and 9 depict the FTIR spectra of the specimens of different mixes cured for 2 and 4 weeks, respectively. It is obvious to observe the similarity in the band locations and the difference is only in the band intensity. The detected bands were interpreted according to many authors [28-31]. The characteristic vibration bands at 3700 and $3625 \mathrm{~cm}^{-1}$ are attributed to the $\mathrm{O}-\mathrm{H}$ stretching of kaolinite and montmorillonite, respectively. These bands intensities decreased as MCW content and curing periods increased. This provides evidence to the diminishing of the clay content (clay dissolution) and new phases formation. The bands at $3400 \mathrm{~cm}^{-1}$ and $1625 \mathrm{~cm}^{-1}$ can be attributed to the stretching vibration of O-H group in $\mathrm{H}_{2} \mathrm{O}$ adsorbed on the specimens. The group of bands found in Fig. 9 at 800, 1450 (large and symmetric peaks) and between $2500-1800 \mathrm{~cm}^{-1}$ can be assigned to the vibration corresponding to the $\mathrm{CO}_{3}{ }^{2-}$ group of calcite. These bands are nearly increased as $\mathrm{HL}$ content increased and MCW decreased. All specimens have complex intensive silicate bands, Si-O, Si-O-Al (octahedral Al), Si-O-Si stretching and bending, as well as $\mathrm{OH}\left(\mathrm{Al}_{2} \mathrm{OH}\right)$ bending bands in the region of $1125-400 \mathrm{~cm}^{-1}$. Generally, it is difficult to interpret this region by studying FTIR-spectra only. Since many forms of silicates give rise to several peaks causing lots of overlaps. The band that appears as a shoulder at 1125 and $675 \mathrm{~cm}^{-1}$ may be related to the un-solubilized silica. These bands decreased as MCW increased as well as curing period progressed. Also, a significance change was observed in the broadness in the band at $1000 \mathrm{~cm}^{-1}$ which gradually increases with the increase of MCW content at the expense of decreasing in the band intensity of the un-solubilized silica. This goes parallel to the XRD results. This is supported by the growth of increasable band, to the Mix R3, at $3400 \mathrm{~cm}^{-1}$ which may be indicative to the formation of pozzolanic reaction products. On the contrary, the specimens of the mix R4 show the smallest peaks at 3400 and $1000 \mathrm{~cm}^{-1}$. Furthermore, at all spectra the alumina and silicate bands are increased as curing times increases till the mix R 3, contains $25 \% \mathrm{MCW}$ and $5 \% \mathrm{HL}$. The band of amorphous silica at $800 \mathrm{~cm}^{-1}$ was observed and increased as curing period increases meaning that the smectite layer became substantially depleted.

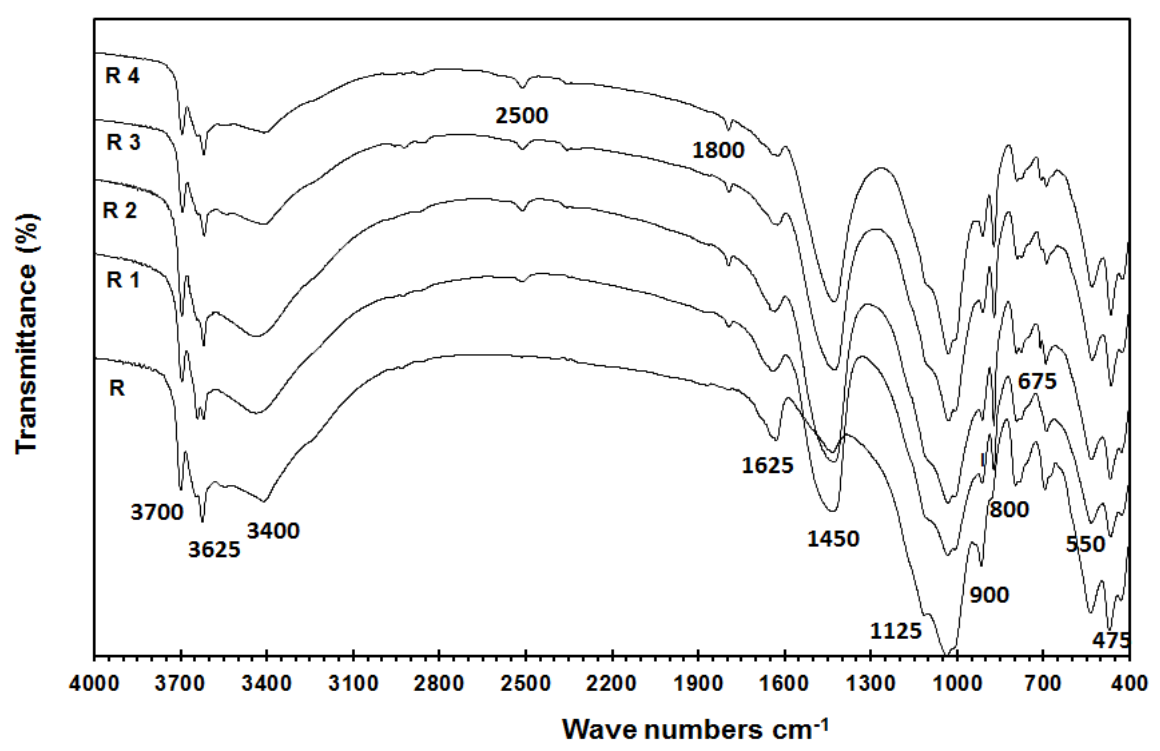

Fig.8. FTIR spectra of the 2 weeks cured specimens of different mixes. 


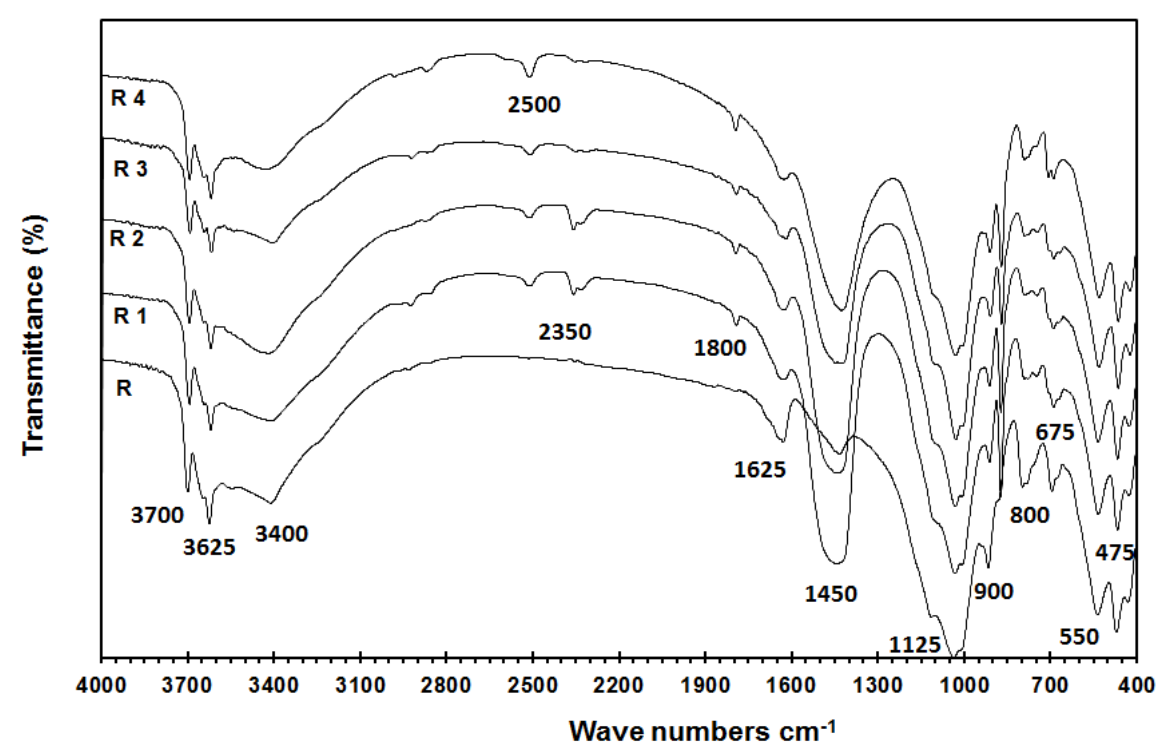

Fig.9. FTIR spectra of the 4 weeks cured specimens of different mixes.

\section{Conclusions}

This research studied the feasibility of using marble cutting waste (MCW) with others additives for stabilizing the clay - based materials to produce a sustainable clay brick. On the basis of the test results obtained from the specimen of the five clay- based mixes cured for 2 and 4 weeks, the following conclusions can be drawn:

- The potential benefit of stabilization was found to depend on the combination of hydrated lime and marble cutting waste.

- $\quad$ The compressed specimens without stabilizers have fake positive properties and that has clearly detected in the result of water soaking test.

- As the curing period proceeds and the MCW increases up to $15 \%$, the specimens properties improved.

- Without the HL, the gypsum and ettringite effect negatively on the properties of the cured specimens.

- The stabilization process effected greatly by the mix $\mathrm{pH}$ where it should be always more than 12 .

- To increase the durability of the stabilized clay bricks, a suitable water and erosion coating proof treatment such as the applied silicon-based paint can be used but the treatment can't stand alone without the stabilizer addition.

\section{Author Contributions}

Author Medhat El-Mahllawy interpreted the data, wrote the manuscript and worked extensively on preparing the manuscript for publication. Author Ayman Kandeel supervised and revised the work. Author Mahmoud Abdel Latif conceived the research idea and participated in the practical work. Author Abdeen El Nagar participated in the practical experiments. All authors contributed to designing the study. 


\section{Conflicts of Interest}

The authors declare no conflict of interest.

\section{References}

1. Reddy, B.;Jagadish, K. Embodied energy of common and alternative building materials and technology. Energy and Buildings 2003, 35, 129-137.

2. Zhang, L. Production of bricks from waste materials- A review. Const. Buil. Mat. 2013, 47, 643-655.

3. Turkmen, I.; Ekinci, E.; Kantarc, F.; Sarc, T. The mechanical and physical properties of unfired earth bricks stabilized with gypsum and Elazig Ferrochrome slag. Int. J. Sus. Buil. Env. 2017, 6,565-573.

4. Siddiqua, S.; Barreto, P. Chemical stabilization of rammed earth using calcium carbide residue and fly ash. Construction and Building Materials 2018, 169, 364-371.

5. Sekhar, D.; Nayak, S. Utilization of granulated blast furnace slag and cement in the manufacture of compressed stabilized earth blocks. Construction and Building Materials 2018, 166,531-536.

6. Sore, S.; Messan, A.; Prud'homme, E.; Escadeillas, G.; Tsobnang, F. Stabilization of compressed earth blocks (CEBs) by geopolymer binder based on local materials from Burkina Faso. Construction and Building Materials 2018, 165, 333-345.

7. Rahman, M.; Rehman, S.; Al-Amoudi, O. Literature review on cement kiln dust usage in soil and waste stabilization and experimental investigation. IJRRAS 2011, 1, 77-87.

8. Zaliha, S.; Kamarudin, H.; Al Bakri, A.; Binhussain, M., Salwa, M. Review on soil stabilization techniques. Aus. J. Basic and Appl. Sci. 2013, 7 (5), 258-265.

9. Galan-Marin, C.; Rivera-Gomez, C.; Petric, J. Clay-based composite stabilized with natural polymer and fiber. Const. Buil. Mat. 2010, 24, 1462-1468.

10. Espuelas, S.; Omer, J.; Marcelino, S.; Echeverria, A.; Seco, A. Magnesium oxide as alternative binder for unfired clay bricks manufacturing. Applied Clay Sci. 2017, 146, $23-26$.

11. Oti, J., Kinuthia, J. Designed non-fired clay mixes for sustainable and low carbon use. Appl. Clay Sci. 2012, 59-60, 131-139.

12. Jawad, I., Taha, M.; Majeed, Z.; Khan, T. Soil stabilization using lime: Advantages and proposing a potential alternative. Res. J. Appl. Sci. Eng. Tech. 2014, 8 (4), 510-520.

13. Zami, M.; Lee, A. Stabilized or unstabilized earth construction for contemporary urban housing. Proc. Int. Conf. Resp. Manuf. Green Manuf . (ICRM) Symposium, Ningbo, China, 2010.

14. El-Sayed, H.; Farag, A.; Kandeel, A.; Younes, A.; Yousef, M. Characteristics of the marble processing powder waste at Shaq El Thoban industrial zone, Egypt and its suitability for cement manufacture. HBRC J. 2016, Article in Press.

15. Mashaly, A.; Shalaby, B.; El-Hefnawi, M. Characterization of the marble sludge of the Shaq El Thoban industrial zone, Egypt and its compatibility for various recycling applications. Aus. J. Basic and appl. Sci. 2012, 6 (3), 153-161.

16. Said R. The geology of Egypt, $3^{\text {rd }}$ ed; Elsevier Publ. Co.: Amesterdam, Holland, 1962.

17. ASTM D7348. Standard test methods for loss on ignition (LOI) of solid combustion residues. USA: Standard Annual Book of ASTM Standards, 05.06; 2008.

18. ASTM D 4972. Standard test method for $\mathrm{pH}$ of soils. USA: Standard Annual Book of ASTM Standards, 04.08; 2013.

19. Oti, J.; Kinuthia, J.; Bai, J. Engineering properties of unfired clay masonry bricks. Engineering Geology 2009, 107, 130-139. 
20. Millogo, Y.; Hajjaji, M.; Ouedraogo, R. Microstructure and physical properties of lime-clayey adobe bricks. Construction and Building Materials 2008, 22, 2386-22392.

21. Bahar, R.; Benazzoug, M.; Kenai, S. Performance of compacted cement-stabilised soil. Cement and Concrete Composites 2004, 26 (7), 811-820.

22. Egyptian Code for the Building by the Soil (ECBS). The building by the stabilized and compressed earth blocks 2016, 1, 1-144.

23. Egyptian Standard Specification (ESS). Quick and Hydrated Lime. Definitions, Requirements and Conformity Criteria 2008, 1, Egypt.

24. El-Mahllawy, M. Effect of activation of granulated blast-furnace slag on the properties of unfired eco-friendly clay bricks. Proc. 1st Int. Conf. on Innovative Buil. Mat. Egypt, Dec, 2014.

25. El-Mahllawy, M.; Kandeel, A. Engineering and mineralogical characteristics of stabilized unfired montmorillonitic clay bricks. HBRC J. 2014, 10 (1), 82-91.

26. Nair, S.; Little, D. Mechanisms of distress associated with sulfate-induced heaving in lime-treated soils. Transp. Res. Record: J. Trans. Res. Board 2011, 2212 (1), 82-90.

27. Abd Elaty, M.; Ghazy, M. Performance of Portland cement mixes containing silica fume and mixed with lime-water. HBRC J. 2014, 10 (3), 247-257.

28. Choller, M.; Horgnies, M. Analyses of the surface of concrete by Raman and FT-IR spectroscopies comparative study of hardened samples after demoulding and after organic post-treatment. Surface and Interface Analysis 2010, 43, 714-725.

29. Djomgoue, P.; Njopwouo, D. FT-IR spectroscopy applied for surface clays characterization. J. Surface Eng. Mat. Adv. Tech. 2013, 3, 275-282.

30. Madejova, J. FTIR techniques in clay minerals studies. Vibrational Spectroscopy 2003, 31, 1-10.

31. Yu, P.; Kirkpatrick, R.; Poe, B.; McMillan, P.; Cong, X. Structure of calcium silicate hydrate (C-SH): Near-, mild-, and far-infrared spectroscopy. J. Am. Ceram. Soc. 1999, 82 (3), 742-48. 